\title{
Can the ISO 14595 Method be Used to Validate the Heterogeneity and Composition of Natural Mineral Standards Using WDS And/or EDS?
}

Simon Burgess ${ }^{1}$, Philippe Pinard ${ }^{1}$, Stuart Kearns ${ }^{2}$, Ben Buse ${ }^{2}$, Heather Dyson ${ }^{3}$ and Rosie Jones ${ }^{4}$

${ }^{1}$ Oxford Instruments NanoAnalysis, High Wycombe, England, United Kingdom, ${ }^{2}$ University of Bristol, Bristol, England, United Kingdom, ${ }^{3}$ Micro-analysis Consultants Ltd, St Ives, England, United Kingdom, ${ }^{4}$ Oxford Instruments, High Wycombe, England, United Kingdom

Standards are crucial for the development, practice and validation of quantitative X-ray microanalysis. In addition to being the basis of standard-based quantification by EDS and/or WDS, they are also required for the development of standardless methods where the calibration of each element is done by the system developer/manufacturer [1]. Standards are also needed in all cases to validate that the results being produced by a system are within the required accuracy limits.

Natural minerals are commonly used as standards because they are relatively insensitive to beam damage, resistant to oxidation, and are easily handled and polished for practical use in electron microscopes. They are used to provide standards of similar composition for the analysis of other minerals and ceramics, and for elements that do not form simple stable compounds or pure elements, such as for the analysis of sodium, potassium and calcium.

The main challenge related to the use of natural mineral standards is the complexity of their chemistry, on the macro- and microscale, as well as the potential for the presence of phases of different composition, for example as inclusions in the material. As more powerful analysis tools, with increased sensitivity and spatial resolution, have become available (e.g., fast SDD EDS detectors, FEG-SEM and electron microprobes), some widely used mineral standards are now viewed as being heterogeneous on the microscale. Even when minerals are confirmed to be homogeneous the question remains as to their exact composition. Most minerals used in microanalysis do not have end member stoichiometry, with solid solution / substitution between elements extremely common.

Mineral standards with known or certified compositions have typically been characterised by the same techniques, usually WDS. This characterisation in turn probably used standards for calibration that have the same issues of homogeneity and compositional determination, as it is difficult to find standards whose composition has been verified by other methods. The microanalysis community (e.g., FIGMAS [2]) are now discussing how to catalogue and measure standards, including how to best determine composition and homogeneity.

For this study we have used the ISO 14595 [3] method for the specification of certified reference materials, to determine the suitability and composition of the mineral standards used in our reference standard blocks. ISO 14595 does not specifically address the issues with the quality of the standards that are used for composition determination, therefore we have considered several approaches for determining the composition. One approach is to re-examine the use of simple materials of known composition, such as pure elements or binary compounds [4]. To mitigate against potential errors with matrix corrections we have attempted to find materials and conditions where these corrections are minimised. To further test matrix correction errors each material has been analysed at different accelerating voltages to check the sensitivity of measured composition with changing matrix correction. 
For example, Fig. 1 shows results of the analysis of two mineral standards: albite ( $\left.\mathrm{NaAlSi}_{3} \mathrm{O}_{8}\right)$, and wollastonite $\left(\mathrm{CaSiO}_{3}\right)$, with the matrix corrections applied for their composition calculation. The minerals have been analysed using WDS and EDS using the same processing and collection software (Oxford Instruments AZtec), matrix correction procedure (XPP), and standards. The standards used to measure the composition were: $\mathrm{Na}(\mathrm{NaCl}), \mathrm{Al}\left(\mathrm{Al}_{2} \mathrm{O}_{3}\right.$,), $\mathrm{Si}\left(\mathrm{SiO}_{2}\right), \mathrm{K}(\mathrm{KBr}), \mathrm{Ca}\left(\mathrm{CaF}_{2}\right), \mathrm{Mn}$ (pure $\left.\mathrm{Mn}\right)$ and Fe (pure $\mathrm{Fe})$. Following ISO 14595 the mineral standards were first checked for heterogeneity by collecting 2 acquisitions from 10 different areas and determining the compositional variance from element intensities. The count time was adjusted so at least 100,000 counts for each element were collected for each acquisition giving an uncertainty of less than $0.3 \%$. In Fig. 1 the measured ranges are shown by the bands calculated using the certificated compositions of the standards as the conversion factor.

Fig. 1 shows calculated compositions measured at 10, 15 and 20kV for wollastonite and at 10 and $20 \mathrm{kV}$ for albite. The variation in measured composition is similar to the heterogeneity measured for each element with the exception of $\mathrm{Al}$ in albite. The measured composition for calcium in wollastonite is $33.8 \mathrm{wt} \%$, $0.5 \mathrm{wt} \%$ lower than the certificate. This fits well with the stoichiometry of the material which contains $0.5 \mathrm{wt} \% \mathrm{Mn}$ and an additional $0.2 \mathrm{wt} \% \mathrm{Fe}$ (not in the certificate). The measured Si is $0.25 \mathrm{wt} \%$ higher than the certificate, but this is also consistent with the stoichiometry of this mineral. The measured composition of $\mathrm{Na}$ in albite is higher than the certificate, but is too high considering the level of $\mathrm{Ca}$ in this material. This could be due to the large matrix correction, although the result does not change significantly with $\mathrm{kV}$. A more likely explanation being investigated is charging of the $\mathrm{NaCl}$ standard, which lowers the $\mathrm{Na}$ $\mathrm{K}$ intensity. The $\mathrm{Al}$ is the least reproducible result, but fits well with the certificate and with the stoichiometry of the material, and its measured silicon and calcium content.

$\mathrm{SiO}_{2}$ and $\mathrm{CaF}_{2}$ are potential candidates for initial composition determination of some minerals. Matrix corrections for albite using $\mathrm{Al}_{2} \mathrm{O}_{3}$ and $\mathrm{NaCl}$ are larger, but variations with accelerating voltage are similar to those seen in wollastonite. The use of these standards, in particular $\mathrm{NaCl}$, requires further investigation. This initial study is being expanded to include more materials, measurements by different methods, instruments and standard calibrations and other approaches. For example, we are measuring the degree of internal inconsistency; i.e. using each mineral standard as a primary calibration standard and then measuring other standards as 'unknowns' to test the consistency of a large number of mineral standard compositions. 

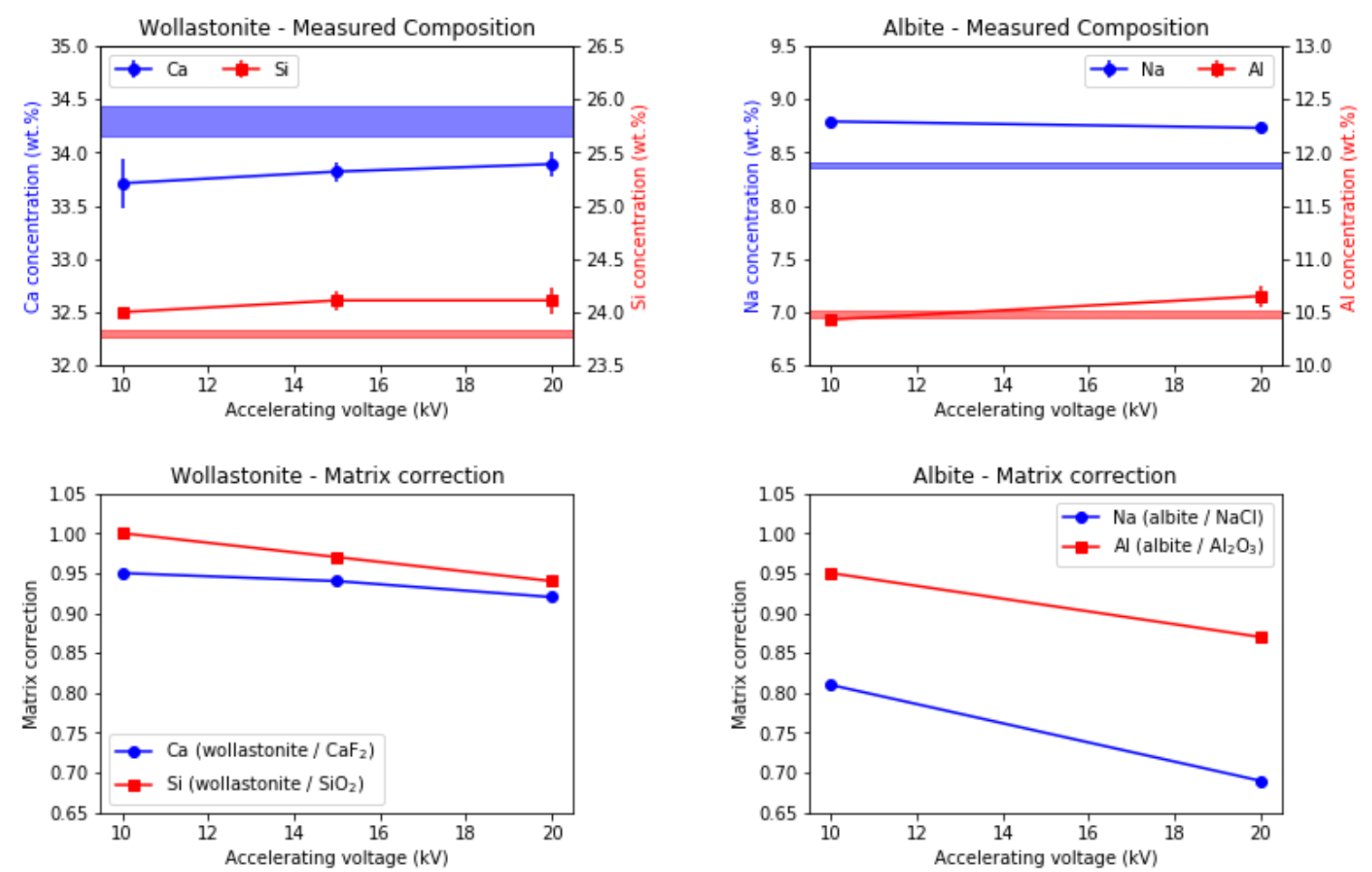

Figure 1. Calculated compositions and matrix corrections for $\mathrm{Ca}$ and $\mathrm{Si}$ in wollastonite and $\mathrm{Na}$ and $\mathrm{Al}$ in albite measured using EDS at different accelerating voltages. Compositions are compared to expected compositional bands calculated from the certificate composition of each standard and their measured heterogeneity. "Matrix Correction" is the ratio of factors for sample and standard.

\section{References}

[1] P Pinard et al, EMAS 2018 Proceedings (2018), 269

[2] J Allaz et al, Microsc. Microanal. 21 S3 (2015), 2019

[3] ISO14595:2014

[4] TR Sweatman and JVP Long, J. Pet 10 (1969), 332 